\title{
Cost-Effectiveness of Ferrous Fumarate-Folic Acid and Ferrous Gluconate-Multivitamins in a High Prevalence Area of Iron Deficiency Anemia in Indonesia
}

\author{
Yasinta Rakanita (iD) ${ }^{1,2}$ \\ Mas Rizky AA Syamsunarno 3 \\ Rano K Sinuraya (iD) I,4 \\ Eka W Suradji $i^{5,6}$ \\ Rizky Abdulah (D) 1,4 \\ Auliya A Suwantika (D) 1,4,7 \\ 'Department of Pharmacology and \\ Clinical Pharmacy, Faculty of Pharmacy, \\ Universitas Padjadjaran, Bandung, \\ Indonesia; ${ }^{2}$ College of Pharmaceutical \\ Sciences Pelita Mas, Palu, Indonesia; \\ ${ }^{3}$ Department of Biomedical Sciences, \\ Faculty of Medicine, Universitas \\ Padjadjaran, Bandung, Indonesia; ${ }^{4}$ Center \\ of Excellence in Higher Education for \\ Pharmaceutical Care Innovation, \\ Universitas Padjadjaran, Bandung, \\ Indonesia; ${ }^{5}$ Department of Public Health, \\ Faculty of Medicine, Krida Wacana \\ University, Jakarta, Indonesia; ${ }^{6}$ UKRIDA \\ Hospital, Jakarta, Indonesia; ${ }^{7}$ Center for \\ Health Technology Assessment, \\ Universitas Padjadjaran, Bandung, \\ Indonesia
}

Background: Up to now, the combinations of ferrous fumarate-folic acid (FF-FA) and ferrous gluconate-multivitamins (FG-MV) have been implemented by the local government in the province of Papua. Nevertheless, there is no a specific economic evaluation that has been applied to investigate the cost-effectiveness of FF-FA and FG-MV.

Objective: This study aimed to investigate the cost-effectiveness of FF-FA and FG-MV to be implemented in Teluk Bintuni, as one of the districts with the highest prevalence of iron deficiency anemia in Papua by taking the healthcare perspective into account.

Methods: A prospective observational study was applied by considering two groups of women (15-49 years old) with iron deficiency anemia who received FF-FA and FG-MV from September to November 2018. Applying a purposive sampling method, respondents were selected from 875 targeted women in six sub-districts, who met inclusion criteria. To estimate the total cost, we applied a healthcare perspective that considered direct medical cost only (eg, the procurement cost of iron tablets, cost of $\mathrm{Hb}$ test, and cost of healthcare visit). To estimate the effectiveness of intervention, we applied two major parameters, such as $\mathrm{Hb}$ level and utility score in quality-adjusted life year (QALY). The cost-effectiveness values were evaluated by using the criteria on the cost-effectiveness of healthcare intervention according to the threshold of gross domestic product (GDP) per capita (cost per QALY gained).

Results: From 875 targeted women in six sub-districts who met inclusion criteria, we found approximately 222 women with moderate-severe iron deficiency anemia and 110 women with complete data in the group of FF-FA $(n=69)$ and FG-MV $(n-41)$. The results showed that there were significant differences $(p$-value $<0.05$ ) on the number of respondents, age, oral iron cost, total healthcare cost and utility score in both intervention groups. Comparing the use of FG-MV with FF-FA, we estimated the incremental cost-effectiveness ratios (ICERs) would be $\$ 255.77$ per controlled patient, $\$ 142.09$ per patient with $\mathrm{Hb}$ increment $>2.00 \mathrm{~g} / \mathrm{dL}, \$ 79.93$ per patient with $\mathrm{Hb}$ increment $>1.00 \mathrm{~g} / \mathrm{dL}$, and $\$ 11.59$ per QALY gained. Conclusion: The ICER was estimated to be $\$ 11.59$ per QALY gained, which was highly costeffective, according to GDP-based cost-effectiveness threshold. In addition, the utility score of women with iron deficiency anemia was considered to be the most influential factor impacting the cost-effectiveness value.

Keywords: ICER, cost per controlled patient, cost per patient with $\mathrm{Hb}$ increment $>2.00 \mathrm{~g} /$ $\mathrm{dL}$, cost per patient with $\mathrm{Hb}$ increment $>1.00 \mathrm{~g} / \mathrm{dL}$, cost per QALY gained
Correspondence: Auliya A Suwantika Department of Pharmacology and Clinical Pharmacy, Faculty of Pharmacy, Universitas Padjadjaran, Bandung, Indonesia

Email auliya@unpad.ac.id 


\section{Introduction}

Iron deficiency anemia is caused by a condition of iron metabolism disorder (eg, increased iron demand, limited external supply, and increased blood loss), which might lead to long-term conditions of insufficient iron. ${ }^{1}$ Several guidelines for the prevention and eradication of anemia have been issued, such as recommended regiment, dosage, cost and effectiveness of alternative interventions, which resulted in the use of iron tablets as one of the recommended interventions to prevent anemia. ${ }^{2-5}$

As one of the provinces with high prevalence of iron deficiency anemia in Indonesia, the use of iron tablets has been adopted by the province of Papua through a specific regulation on the supply chain management of iron tablets. $^{6}$ In 2018, approximately $42.0 \%$ of iron tablets have been distributed successfully in the province of Papua. ${ }^{6}$ Next to distribution rate, there are no relevant indicators that can be used to assess the effectiveness of this intervention. Up to now, the combinations of ferrous fumarate-folic acid (FF-FA) and ferrous gluconate-multivitamins (FG-MV) have been implemented by the local government in the province of Papua. Nevertheless, there is no a specific economic evaluation that has been applied to investigate the cost-effectiveness of FF-FA and FG-MV. According to the guidelines on the management of iron deficiency anemia, the selection of iron supplementation should be based on its cost-effectiveness. ${ }^{7}$ Hence, this study aimed to investigate the cost-effectiveness of FFFA and FG-MV to be implemented in Teluk Bintuni, as one of the districts with the highest prevalence of iron deficiency anemia in Papua by taking the healthcare perspective into account.

\section{Methods}

A prospective observational study was applied by considering two groups of women with iron deficiency anemia who received FF-FA and FG-MV from September to November 2018. We classified mild, moderate and severe iron deficiency anemia based on the concentrations of hemoglobin $(\mathrm{Hb})$ in the blood. Mild iron deficiency anemia corresponded to a level of $\mathrm{Hb}$ concentration of 10.0$10.9 \mathrm{~g} / \mathrm{dL}$ and $11.0-11.9 \mathrm{~g} / \mathrm{dL}$ for pregnant and nonpregnant women, respectively. ${ }^{8}$ Moderate iron deficiency anemia corresponded to a level of 7.0-9.9 g/dL and 8.0$10.9 \mathrm{~g} / \mathrm{dL}$ for pregnant and non-pregnant women, respectively. ${ }^{8}$ Meanwhile, severe iron deficiency anemia corresponded to a level less than $7.0 \mathrm{~g} / \mathrm{dL}$ and $8.0 \mathrm{~g} / \mathrm{dL}$ for pregnant and non-pregnant women, respectively. ${ }^{8}$ Applying a purposive sampling method, respondents were selected from 875 targeted women in six subdistricts, who met inclusion criteria (eg, 15-49 years old pregnant and non-pregnant women with moderate and severe iron deficiency anemia). All these participants, including under 18 years old, signed an informed consent on their own behalf to allow a 30-day intervention. The response to treatment was monitored in 4 weeks since the $\mathrm{Hb}$ level should increase within this period, although an improvement can also be obtained after a few days. ${ }^{9}$ Respondents with incomplete data would be excluded. To measure the $\mathrm{Hb}$ level, a portable HemoCue analyzer (HemoCue 201 ${ }^{\mathrm{TM}}$, Angelholm, Sweden) was used in selected sub-districts from rural (Kaitaro, Aranday, Tembuni and Meyado) and urban area (Manimeri and Bintuni). The ethical permission for this study was obtained from the Ethics Committee of Universitas Padjadjaran, Indonesia (approval number: 172/UN6.KEP/EC/2018) and this study was conducted in accordance with the Declaration of Helsinki. In addition, participants under 18 years of age were approved by the ethics committee to provide informed consent on their own behalf.

To estimate the costs of FF-FA and FG-MV treatment, we applied the healthcare perspective that considered direct medical cost only. ${ }^{10,11}$ For direct medical costs, we calculated the procurement cost of iron tablets, cost of $\mathrm{Hb}$ test, and cost of healthcare visit, which represented all costs covered by the local government. To estimate the effectiveness of intervention, we applied two major parameters, such as $\mathrm{Hb}$ level and utility score in qualityadjusted life year (QALY). Several criteria were selected to apply $\mathrm{Hb}$ level as the effectiveness parameters, such as the number of controlled patients who gained normal $\mathrm{Hb}$ due to intervention $(11.00 \mathrm{~g} / \mathrm{dL}$ and $12.00 \mathrm{~g} / \mathrm{dL}$ for pregnant and non-pregnant women, respectively), ${ }^{12}$ the number of patients with minimal $\mathrm{Hb}$ increment at $2.00 \mathrm{~g} / \mathrm{dL},{ }^{13}$ and $1.00 \mathrm{~g} / \mathrm{dL}$ during 30 days. ${ }^{14}$ To assess patients' utility score, we used a generic tool from EuroQol entitled EuroQol-5 Dimensions-5 Levels (EQ5D5L), which can measure the quality of life from five dimensions (eg, abilities to mobility, self-care, usual activities, pain or discomfort and anxiety or depression) within the Indonesian value set. ${ }^{15}$

To estimate the incremental cost-effectiveness ratio (ICER), we used this following formula: 


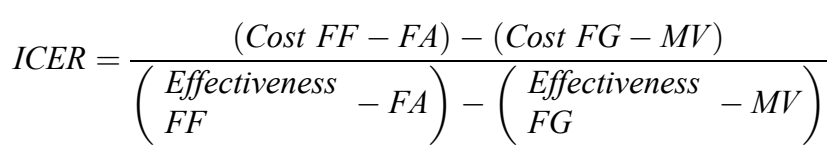

The cost-effectiveness values were evaluated by using the criteria on the cost-effectiveness of healthcare intervention according to the threshold of gross domestic product (GDP) per capita (cost per QALY gained): (i) highly cost-effective (less than one GDP per capita); (ii) cost-effective (between 1-3 times GDP per capita); and (iii) cost-ineffective (more than 3 times GDP per capita) [10]. Univariate sensitivity analysis was performed to investigate the effects of different input parameters on cost and health outcomes, by varying each parameter at value of $\pm 25 \%$ while keeping other parameters constant. ${ }^{16,17}$

\section{Results}

From 875 targeted women in six sub-districts who met inclusion criteria, we found approximately 222 women with moderate-severe iron deficiency anemia and 110 women with complete data in the group of FF-FA $(n=69)$ and FG-MV (n-41). The results showed that there was a significant difference on the number of respondents in both intervention groups in each district ( $p$-value $=0.02$ ). Furthermore, there was also a significant difference of age in both intervention groups ( $p$-value $=0.02$ ). The result showed that the majority of respondents $(61.8 \%)$ with moderate-severe iron deficiency anemia were adolescent girls (15-20 years old), specifically in Teluk Bintuni. For respondents' ethnicity and $\mathrm{Hb}$ level, there were insignificant differences in both intervention groups ( $p$-value $<0.05)$. More detailed information about the characteristics of respondents can be seen in Table 1.

We applied several parameters to estimate the costeffectiveness value. The results showed that there were significant differences on oral iron cost, total healthcare cost and utility score in both intervention groups ( $p$-value $<0.05$ ) (see Table 2). In a comparison with FF-FA, FG-MV was considered to be less costly, yet less effective. We estimated the ICERs would be $\$ 255.77$ per controlled patient, $\$ 142.09$ per patient with $\mathrm{Hb}$ increment $>2.00 \mathrm{~g} /$ $\mathrm{dL}, \$ 79.93$ per patient with $\mathrm{Hb}$ increment $>1.00 \mathrm{~g} / \mathrm{dL}$, and $\$ 11.59$ per QALY gained (see Figure 1). Applying GDP per capita of Indonesia (\$3894) as the threshold of costeffectiveness in the context of cost per QALY gained, the use FG-MV can be considered to be highly cost-effective. In particular, the result of sensitivity analysis showed that the utility score of patients in the group of FF-FA was considered to be the most influential factor impacting the cost-effectiveness value (see Figure 2).

\section{Discussion}

The results showed that there were significant differences on the number of respondents in each district and age in both intervention groups, which might be caused by specific socio-demographic factors. The number of women with moderate-severe iron deficiency anemia in urban area (Manimeri and Bintuni) was reported to be higher than in rural area (Kaitaro, Aranday, Tembuni and Meyado) due to higher number of urban population than rural population. The population density in Manimeri and Bintuni were reported to be 18.55 and 56.87 people/kilometer square, respectively. These numbers were much higher than the population density in Aranday (1.89 people/kilometer square), Meyado (1.50 people/kilometer square), Kaitaro (0.92 people/kilometer square), and Tembuni (0.69 people/kilometer square) ${ }^{18}$ The result of this study is similar to the result of a previous study on the adherence to iron-folate supplement for pregnant women in Northern Ethiopia, which took 182 respondents from urban area and only 18 respondents from rural area. ${ }^{19}$ In addition, it should be highlighted that supplementation program in Indonesia is monitored by the primary healthcare centers, where the activities in urban area were reported to be more active with higher patients' compliance level than in rural area. ${ }^{20}$ In a comparison with women in urban area, women in rural area tend to have more limited knowledge about the benefits of oral iron treatment. ${ }^{21}$ Furthermore, the result of this study found that young women (15-20 years old) dominantly experience moderate-to-severe iron deficiency anemia, which is similar with the result of a previous study in India that mentioned the highest prevalence of iron deficiency anemia was found in adolescent girls (10-19 years old). ${ }^{22}$ These findings also strengthen the result of a previous study by Righetti et al, which mentioned that young women need more iron cellular and riboflavin than older women. ${ }^{23}$

Two major parameters of $\mathrm{Hb}$ level and utility score were applied to assess the effectiveness of intervention. As the clinical outcome in this study, Hb level was measured twice, before and after intervention. We found 9 women ( 7 in FF-FA and 2 in FG-MV) who gained normal $\mathrm{Hb}$ level after a 30-day intervention, whilst several guidelines mentioned that the use of oral iron therapy might require at least 90 days to gain normal $\mathrm{Hb}$ level. ${ }^{2,8,24} \mathrm{In}$ 
Table I Characteristics of Respondents

\begin{tabular}{|c|c|c|c|c|}
\hline Characteristics & Total $(n=\mid 10)$ & FF-FA $(n=69)$ & FG-MV $(n=4 I)$ & $p$-value \\
\hline $\begin{array}{l}\text { Residence } \\
\text { Bintuni (urban) } \\
\text { Manimeri (urban) } \\
\text { Aranday (rural) } \\
\text { Meyado (rural) } \\
\text { Kaitaro (rural) } \\
\text { Tembuni (rural) }\end{array}$ & $\begin{array}{c}40(36.37 \%) \\
34(30.91 \%) \\
6(5.45 \%) \\
17(15.46 \%) \\
7(6.36 \%) \\
6(5.45 \%)\end{array}$ & $\begin{array}{c}29(42.03 \%) \\
23(33.33 \%) \\
0(0.00 \%) \\
7(10.14 \%) \\
5(7.25 \%) \\
5(7.25 \%)\end{array}$ & $\begin{array}{c}\text { II }(26.83 \%) \\
\text { II }(26.83 \%) \\
6(14.63 \%) \\
\text { I0 }(24.40 \%) \\
2(4.88 \%) \\
\text { I }(2.43 \%)\end{array}$ & $0.02 *$ \\
\hline $\begin{array}{l}\text { Age } \\
\begin{aligned} 15-20 \\
21-25 \\
26-30 \\
31-35 \\
36-40 \\
4 I-45 \\
46-49\end{aligned}\end{array}$ & $\begin{array}{c}68(61.82 \%) \\
10(9.09 \%) \\
10(9.09 \%) \\
9(8.18 \%) \\
7(6.36 \%) \\
5(4.55 \%) \\
1(0.91 \%)\end{array}$ & $\begin{array}{c}49 \text { (71.01\%) } \\
4(5.80 \%) \\
4(5.80 \%) \\
6(8.70 \%) \\
4(5.80 \%) \\
1(1.45 \%) \\
\text { I (I.44\%) }\end{array}$ & $\begin{array}{l}19(46.34 \%) \\
6(14.64 \%) \\
6(14.64 \%) \\
3(7.31 \%) \\
3(7.31 \%) \\
4(9.76 \%) \\
0(0.00 \%)\end{array}$ & $0.02 *$ \\
\hline $\begin{array}{l}\text { Ethnicity } \\
\text { Papuan } \\
\text { Non-Papuan }\end{array}$ & $\begin{array}{l}73(66.36 \%) \\
37(33.64 \%)\end{array}$ & $\begin{array}{l}46(66.67 \%) \\
23(33.33 \%)\end{array}$ & $\begin{array}{l}27(65.85 \%) \\
14(34.15 \%)\end{array}$ & 0.93 \\
\hline $\begin{array}{l}\text { Severity of anemia } \\
\text { Pre intervention } \\
\text { Severe } \\
\text { Moderate } \\
\text { Mild } \\
\text { Normal } \\
\text { Post intervention } \\
\text { Severe } \\
\text { Moderate } \\
\text { Mild } \\
\text { Normal }\end{array}$ & $\begin{array}{c}16(14.55 \%) \\
94(85.45 \%) \\
0(0.00 \%) \\
0(0.00 \%) \\
11(10.00 \%) \\
55(50.00 \%) \\
31(28.18 \%) \\
13(11.82 \%)\end{array}$ & $\begin{array}{c}13(18.84 \%) \\
56(81.16 \%) \\
0(0.00 \%) \\
0(0.00 \%) \\
9(13.04 \%) \\
30(43.48 \%) \\
21(30.44 \%) \\
9(13.04 \%)\end{array}$ & $\begin{array}{c}3(7.32 \%) \\
38(92.68 \%) \\
0(0.00 \%) \\
0(0.00 \%) \\
2(4.88 \%) \\
25(60.98 \%) \\
10(24.39 \%) \\
4(9.75 \%)\end{array}$ & 0.79 \\
\hline
\end{tabular}

Note: *Statistically significant ( $p$-value $<0.05)$.

Abbreviations: FF-FA, ferrous fumarate-folic acid; FG-MV, ferrous gluconate-multivitamin.

Table 2 Parameter of Cost and Effectiveness

\begin{tabular}{|c|c|c|c|}
\hline \multirow[t]{2}{*}{ Parameter } & \multicolumn{2}{|c|}{ Group } & \multirow[t]{2}{*}{$p$-value } \\
\hline & FF-FA $(n=69)$ & FG-MV $(n=4 I)$ & \\
\hline Cost of oral iron & $\$ 3.80$ & $\$ 2.07$ & $0.00 *$ \\
\hline Cost of $\mathrm{Hb}$ test & $\$ 7.32$ & $\$ 7.32$ & 1.00 \\
\hline Cost of healthcare visit & $\$ 32.02$ & $\$ 32.02$ & 1.00 \\
\hline Total healthcare cost & $\$ 43.14$ & $\$ 4 I .41$ & $0.00 *$ \\
\hline Number of controlled patients who gained normal $\mathrm{Hb}$ & 7 & 2 & 0.30 \\
\hline Number of patients with $\mathrm{Hb}$ increment $>2.00 \mathrm{~g} / \mathrm{dL}$ & 15 & 6 & 0.35 \\
\hline Number of patients with $\mathrm{Hb}$ increment $>1.00 \mathrm{~g} / \mathrm{dL}$ & 33 & 17 & 0.52 \\
\hline Utility (QALY) & 2.33 & 1.23 & $0.00 *$ \\
\hline
\end{tabular}

Note: $*$ Statistically significant ( $p$-value $<0.05)$.

Abbreviations: FF-FA, ferrous fumarate-folic acid; FG-MV, ferrous gluconate-multivitamins; Hb, hemoglobin; QALY, quality-adjusted life year. 


\section{ICER}

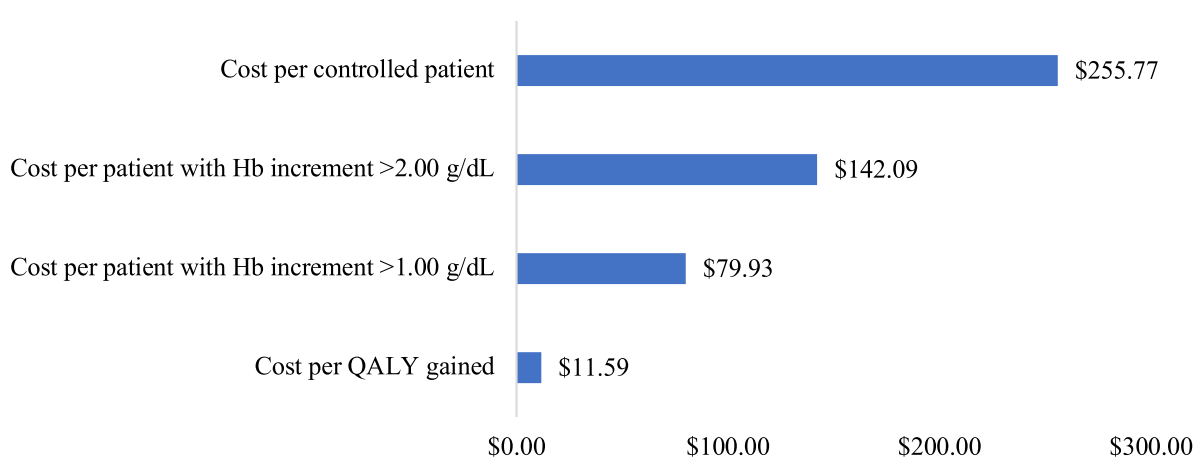

Figure I Incremental cost-effectiveness ratio (ICER).

\section{Sensitivity Analysis}

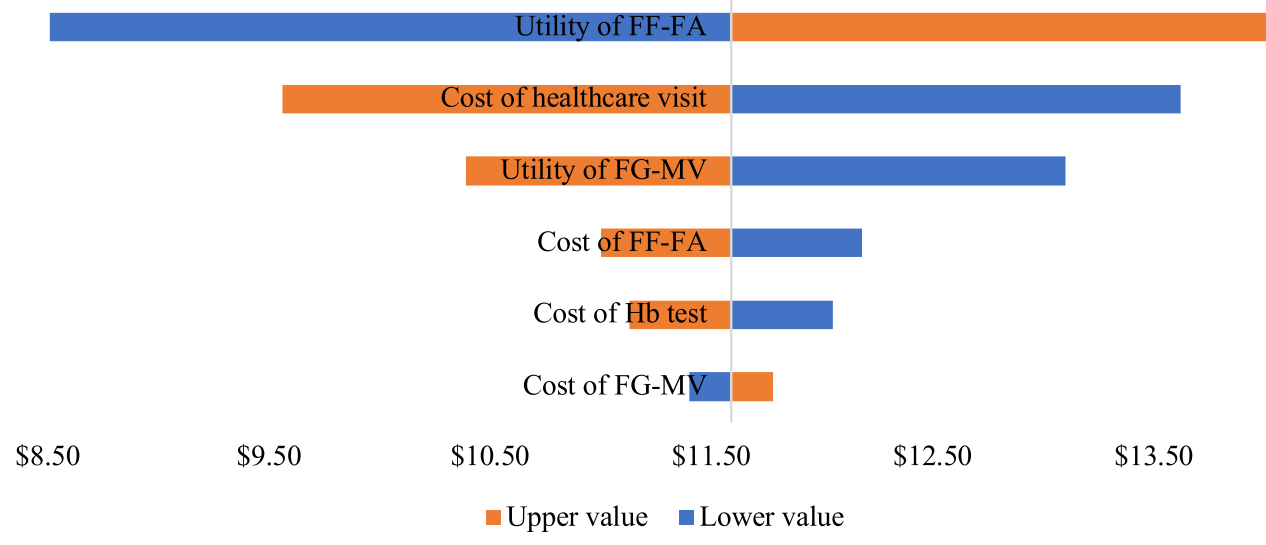

Figure 2 One-way sensitivity analysis.

particular, we applied two other different cut-off values to compare the progression of iron deficiency anemia status, such as number of patients with $\mathrm{Hb}$ increment $>2.00 \mathrm{~g} / \mathrm{dL}$ and $>1.00 \mathrm{~g} / \mathrm{dL}$, according to the WHO's guideline. ${ }^{25}$ This approach was applied since every woman with iron deficiency anemia has a different condition and nutrient intake. In addition, utility score in QALY was applied as the effectiveness intervention since iron deficiency anemia was reported to be an independent risk factor for decreased health-related quality of life in older individuals, according to a large population-based cohort study. ${ }^{26}$ In this study, we found a significant difference of utility score in FF-FA (2.33 QALYs) and FG-MV (1.23 QALYs).

To estimate the cost-effectiveness value, we considered only the healthcare perspective by taking direct medical costs into account, which is very relevant with the current situation since the local government is facing the biggest challenges in the efforts to manage various healthcare programs within limited resources. In this study, we estimated the relevant costs that the healthcare provider spent in providing oral iron treatment for iron deficiency anemia women. Annually, the government provides 200 iron tablets (FF-FA or FG-MV) per pregnant or reproductive woman. Nevertheless, there was a lack of costeffectiveness study on the use of oral iron treatment in Indonesia. This study took into account the potential switch of FG-MV into FF-FA to be implemented in a high prevalence area of iron deficiency anemia in Indonesia. As the current treatment, FF-FA has been used since 2017 in Teluk Bintuni. As the potential alternative, FG-MV is available in the private market and more accessible than FF-FA. The result showed the healthcare provider required $\$ 43.14$ and $\$ 41.41$ per patient to provide FF-FA and FG-MV, respectively. Utility scores that could be yielded were 2.33 QALYs and 1.23 QALY in the group of FF-FA and FG-MV, respectively. As the new 
intervention, it can be interpreted that FG-MV was less costly and less effective than FF-FA. The ICER was estimated to be $\$ 11.59$ per QALY gained, which was highly cost-effective, according to GDP-based cost-effectiveness threshold. In addition, the utility score of women with iron deficiency anemia was considered to be the most influential factor impacting the cost-effectiveness value, which strengthened a recent study by Wouters et al that highlighted a significant association between women with anemia and lower health-related quality of life. ${ }^{26}$

Despite the fact that FF or FG was available in a single formula, the use of these oral tablets in this study was combined with other complements, such as FA and MV. One of the major novelties of this study is to make a comparison between the potential combination of FGMV and FF-FA. In a country with a limited budget, such as Indonesia, it is critical to analyze the cost-effectiveness of new interventions by making a comparison with the current treatment. The more economic evaluations, the better resources for the stakeholder on making evidence-based decisions. ${ }^{27,28}$ Next to the novelty, several limitations were found in this study. Firstly, we considered this study from the healthcare perspective only. We did not consider costs from other perspectives, such as the societal perspective that could estimate direct non-medical and indirect costs. Secondly, we did not take into account the capital costs that might lead the policy makers into poor resourceallocation decisions. Thirdly, compliance to oral iron supplementation was not explored in this study. Even though iron supplementation programs have traditionally been delivered through health centers in Indonesia, the compliance remains a big problem. Taking into account these limitations in the further study is required to complete the recommendation of this initial study. Because country situations and programmatic challenges vary so greatly in Indonesia, the result of this study is expected to assist the stakeholder on developing guidelines and criteria of oral iron treatment by considering national health policies, needs, priorities and resources within local values and preferences.

\section{Conclusion}

In the context of total healthcare cost per patient, approximately \$43.14 and \$41.41 were required to provide FF-FA and FG-MV, respectively. Utility scores that could be yielded were 2.33 QALYs and 1.23 QALY in the group of FF-FA and FG$\mathrm{MV}$, respectively. As the new intervention, it can be interpreted that FG-MV was less costly and less effective than FF-FA. The ICER was estimated to be $\$ 11.59$ per QALY gained, which was highly cost-effective, according to GDP-based costeffectiveness threshold. In addition, the utility score of women with iron deficiency anemia was considered to be the most influential factor impacting the cost-effectiveness value.

\section{Acknowledgment}

This research was supported by grants-in-aid from Universitas Padjadjaran and Teluk Bintuni Hospital for RKS and EWS, respectively. In addition, YR received Doctoral Scholarship from the Ministry of Research, Technology and Higher Education, Republic of Indonesia.

\section{Disclosure}

The authors report no conflicts of interest in this work.

\section{References}

1. Muñoz M, Gómez-Ramírez S, Campos A, Ruiz J, Liumbruno GM. Pre-operative anaemia: prevalence, consequences and approaches to management. Blood Transfus. 2015;13(3):370-379.

2. Low MS, Speedy J, Styles CE, De-Regil LM, Pasricha SR. Daily iron supplementation for improving anaemia, iron status and health in menstruating women. Cochrane Database Syst Rev. 2016;18(4):CD009747.

3. Peña-Rosas JP, De-Regil LM, Garcia-Casal MN, Dowswell T. Daily oral iron supplementation during pregnancy. Cochrane Database Syst Rev. 2015;22(7):CD004736.

4. Omotayo MO, Dickin KL, Pelletier DL, Martin SL, Kung'u JK, Stoltzfus RJ. Feasibility of integrating calcium and iron-folate supplementation to prevent preeclampsia and anemia in pregnancy in primary healthcare facilities in Kenya. Matern Child Nutr. 2018;14 Suppl 1(Suppl 1):e12437. doi:10.1111/mcn.12437

5. Goddard AF, James MW, McIntyre AS, Scott BB. British Society of Gastroenterology. Guidelines for the management of iron deficiency anaemia. Gut. 2011;60(10):1309-1316. doi:10.1136/gut.2010.228874

6. Ministry of Health, Republic of Indonesia. Indonesia health profile 2019. Available from: https://pusdatin.kemkes.go.id/resources/down load/pusdatin/profil-kesehatan-indonesia/Profil-Kesehatan-indonesia -2019.pdf. Accessed March 29, 2021.

7. Stoffel NU, von Siebenthal HK, Moretti D, Zimmermann MB. Oral iron supplementation in iron-deficient women: how much and how often? Mol Aspects Med. 2020;75:100865. ISSN 0098-2997. doi:10.1016/j.mam.2020.100865

8. WHO. Haemoglobin concentrations for the diagnosis of anaemia and assessment of severity. Available from: https://www.who.int/vmnis/ indicators/haemoglobin.pdf. Accessed May 30, 2021.

9. WHO. WHO guide to cost-effectiveness analysis. Available from: https://www.who.int/choice/publications/p_2003_generalised_cea. pdf. Accessed May 2, 2021.

10. Ministry of Health, Republic of Indonesia. Guidelines for the implementation of pharmacoeconomic studies. Available from: https://farm alkes.kemkes.go.id/2014/02/pedoman-penerapan-kajianfarmakoekonomi/. Accessed May 2, 2021.

11. Vieth JT, Lane DR. Anemia. Hematol Oncol Clin North Am. 2017;31 (6): 1045-1060.

12. Jimenez K, Kulnigg-Dabsch S, Gasche C. Management of iron deficiency anemia. Gastroenterol Hepatol. 2015;11(4):241-250.

13. Wirth JP, Woodruff BA, Engle-Stone R, et al. Predictors of anemia in women of reproductive age: Biomarkers Reflecting Inflammation and Nutritional Determinants of Anemia (BRINDA) project. Am J Clin Nutr. 2017;106(Suppl 1):416S-427S. 
14. Purba FD, Hunfeld JAM, Iskandarsyah A, et al. The Indonesian EQ-5D-5L value set. Pharmacoeconomics. 2017;35(11):1153-1165. doi:10.1007/s40273-017-0538-9

15. Suwantika AA, Beutels P, Postma MJ. Cost-effectiveness of hepatitis A vaccination in Indonesia. Hum Vaccin Immunother. 2014;10 (8):2342-2349. doi:10.4161/hv.29353

16. Suwantika AA, Postma MJ. Effect of breastfeeding promotion interventions on cost-effectiveness of rotavirus immunization in Indonesia. BMC Public Health. 2013;13:1106. doi:10.1186/14712458-13-1106

17. Gebremichael TG, Haftu H, Gereziher TA. Time to start and adherence to iron-folate supplement for pregnant women in antenatal care follow up; Northern Ethiopia. Patient Prefer Adherence. 2019;13 (13):1057-1063. doi:10.2147/PPA.S184168

18. Statistic of Teluk Bintuni. Teluk Bintuni in figures 2018. Available from: https://telukbintunikab.bps.go.id/publication/2018/08/16/ a1f42a213befce2e09aa2fb8/kabupaten-teluk-bintuni-dalam-angka -2018.html. Accessed May 30, 2021.

19. Onyeneho NG, I'Aronu N, Chukwu N, Agbawodikeizu UP, Chalupowski M, Subramanian SV. Factors associated with compliance to recommended micronutrients uptake for prevention of anemia during pregnancy in urban, peri-urban, and rural communities in Southeast Nigeria. J Health Popul Nutr. 2016;35(1):35. doi:10. 1186/s41043-016-0068-7

20. Liu D, Cheng Y, Dang S, et al. Maternal adherence to micronutrient supplementation before and during pregnancy in Northwest China: a large-scale population-based cross-sectional survey. BMJ Open. 2019;9(8):e028843. doi:10.1136/bmjopen-2018-028843

21. Nisar YB, Alam A, Aurangzeb B, Dibley MJ. Perceptions of antenatal iron-folic acid supplements in urban and rural Pakistan: a qualitative study. BMC Pregnancy Childbirth. 2014;14(1):344. doi:10.1186/1471-2393-14-344
22. Kumari R, Bharti RK, Singh K, et al. Prevalence of iron deficiency and iron deficiency anaemia in adolescent girls in a tertiary care hospital. J Clin Diagn Res. 2017;11(8):BC04-BC06.

23. Righetti AA, Koua AY, Adiossan LG, et al. Etiology of anemia among infants, school-aged children, and young non-pregnant women in different settings of South-Central Cote d'Ivoire. Am J Trop Med Hyg. 2012;87(3):425-434. doi:10.4269/ajtmh.2012.110788

24. Okam MM, Koch TA, Tran MH. Iron supplementation, response in iron-deficiency anemia: analysis of five trials. Am J Med. 2017;130 (8):991.e1-991.e8. doi:10.1016/j.amjmed.2017.03.045

25. WHO. Guidelines on food fortification with micronutrients. Available from: https://www.who.int/publications/i/item/9241594012. Accessed May 2, 2021.

26. Wouters HJCM, van der Klauw MM, de Witte T, et al. Association of anemia with health-related quality of life and survival: a large population-based cohort study. Haematologica. 2019;104 (3):468-476. doi:10.3324/haematol.2018.195552

27. Suwantika AA, Zakiyah N, Lestari K, Postma MJ. Accelerating the introduction of rotavirus immunization in Indonesia. Expert Rev Vaccines. 2014;13(4):463-472. doi:10.1586/14760584.2014. 891940

28. Abdulah R, Suwandiman TF, Handayani N, et al. Incidence, causative drugs, and economic consequences of drug-induced SJS, TEN, and SJS-TEN overlap and potential drug-drug interactions during treatment: a retrospective analysis at an Indonesian referral hospital. Ther Clin Risk Manag. 2017;13:919-925. doi:10.2147/TCRM. S142226
Therapeutics and Clinical Risk Management

\section{Publish your work in this journal}

Therapeutics and Clinical Risk Management is an international, peerreviewed journal of clinical therapeutics and risk management, focusing on concise rapid reporting of clinical studies in all therapeutic areas, outcomes, safety, and programs for the effective, safe, and sustained use of medicines. This journal is indexed on PubMed Central, CAS,

\section{Dovepress}

EMBase, Scopus and the Elsevier Bibliographic databases. The manuscript management system is completely online and includes a very quick and fair peer-review system, which is all easy to use. Visit http://www.dovepress.com/testimonials.php to read real quotes from published authors. 